\title{
PERANCANGAN SISTEM PENGUMPULAN MINYAK JELANTAH DI APARTEMEN BASSURA CITY
}

\author{
Raden Jachryandestama ${ }^{1^{*}}$, Sirin Fairus ${ }^{2}$, Prismita Nursetyowati ${ }^{2}$ \\ ${ }^{1}$ Program Studi Teknik Industri, ${ }^{2}$ Program Studi Teknik Lingkungan, \\ Fakultas IImu dan Teknologi Komputer, Universitas Bakrie, Indonesia \\ E-mail: raden.jachryandestama@bakrie.ac.id*, sirin.fairus@bakrie.ac.id, prismita.nursetyowati@bakrie.ac.id \\ Received: July 9, 2021 / Revised: July 22, 2021 / Accepted: July 26, 2021 \\ DOI: https://doi.org/10.36782/ijsr.v3i2.87
}

\begin{abstract}
ABSTRAK
Minyak goreng bekas atau minyak jelantah (UCO: Used Cooking Oil) adalah minyak yang telah digunakan untuk memasak di restoran, hotel, industri makanan, dan rumah tangga. Limbah tersebut berbahaya jika dibuang sembarangan karena dapat mengganggu sistem saluran pembuangan atau didaur ulang secara ilegal. Untuk mengatasi hal tersebut, DKI Jakarta merancang rantai pasok UCO menjadi Biodiesel dalam Peraturan Gubernur nomor 167 Tahun 2016. Namun, hingga kini belum mampu mengelola rumah tangga meski berpotensi menghasilkan 210.465,31 liter UCO per hari. Tujuan dari pengabdian masyarakat ini adalah untuk menciptakan sistem pengumpulan dan meningkatkan kesadaran akan bahaya dan potensi UCO di Apartemen Bassura City yang terletak di Jakarta Timur. Sistem pemungutan mempertimbangkan keberlanjutan tidak hanya dari segi lingkungan tetapi juga sosial dan ekonomi. Pengabdian masyarakat dibagi menjadi lima langkah: menciptakan kemitraan lokal, perencanaan rantai pasokan, peningkatan kesadaran melalui sosialisasi, pemantauan dan evaluasi. Kemitraan lokal dibangun antara masjid lokal Al-Falah sebagai pengumpul UCO lokal, BeliJelantah pengumpul UCO menengah, dan Universitas Bakrie. UCO yang dikumpulkan oleh Al-Falah dibeli oleh BeliJelantah dengan harga Rp4.000,00/liter. BeliJelantah menyediakan perlengkapan dasar seperti jerigen dan saringan. Sosialisasi dilakukan secara rutin sebelum khutbah dan secara online karena pembatasan Covid-19. Sejak diterapkannya sistem pengumpulan, masjid Al-Falah telah mengumpulkan 33 liter yang dikonversi menjadi Rp134.000,00. Keberlanjutan pengumpulan minyak jelantah akan dilakukan oleh warga dan pihak DKM Masjid dengan langsung berkoordinasi dengan BeliJelantah dengan pengambilan minimum 2 jeriken bervolume 18 liter atau setara 36 liter. Sistem ini dapat ditingkatkan dengan meningkatkan kemitraan dengan lebih banyak kelompok lokal dan manajemen lokal.
\end{abstract}

Kata kunci: Biodiesel, Limbah Minyak Goreng, Minyak Jelantah, Rantai Pasok.

\begin{abstract}
Used cooking oil are oils that have been used for cooking in restaurants, hotels, food industries, and households. They are dangerous waste when inappropriately disposed since it can interrupt the sewer system or be illegally reprocessed. To combat the issue, the government of Jakarta designed the UCO to Biodiesel supply chain in the Governor's Regulation number 167 of 2016. However, it has yet to manage households despite potentially producing 210.465,31 litres of UCO per day. The goal of this community service is to create a collection system and to increase
\end{abstract}


awareness of the dangers and potential of UCO in Bassura City Apartment, located in East Jakarta, which did not have UCO collection system. The collection system considers sustainability in terms of not only the environment but also social and economic. The community service is split into five steps: creating local partnerships, supply chain planning, awareness raising by socialization, monitoring and evaluation. Local partnership was created between the local mosque Al-Falah as local UCO collector, BeliJelantah the medium sized UCO collector, and Universitas Bakrie. UCO collected by Al-Falah is bought by BeliJelantah at a rate of Rp4,000.00 /litre. BeliJelantah provides basic equipment such as jerrycans and sieve. Socialization was partially done regularly before sermon and online due to Covid-19 restrictions. Since the implementation of the collection system, Al-Falah mosque has collected 33 Litres which was converted into Rp134,000.00. Sustainability of the collection of used cooking oil will be carried out by residents and the DKM Masjid in direct coordination with BeliJelantah by taking a minimum of 2 jerrycans with a volume of 18 litre or the equivalent of 36 litre. This system can be scaled up by increasing partnerships with more local groups and local management.

Keywords: Biodiesel, Supply Chain, Used Cooking Oil, Waste Cooking Oil.

\section{PENDAHULUAN}

Minyak goreng bekas/minyak jelantah adalah limbah pemakaian minyak goreng yang berasal dari rumah tangga, industri makanan, perhotelan, dan lain-lain (Peraturan Gubernur Provinsi DKI Jakarta Nomor 167 Tahun 2016). Limbah tersebut yang perlu diperhatikan karena berpotensi untuk mempengaruhi kesehatan dan lingkungan (Gkouskos \& Tsoutsos, 2018). Minyak jelantah dapat mengandung senyawa toksik dan karsinogenik. Terlebih, minyak jelantah dapat disalahgunakan dengan merubahnya menjadi minyak curah atau pakan ternak (Kharina dkk., 2018). Minyak jelantah merupakan polutan yang pengaruhnya terlihat lebih jelas di pemukiman, perkotaan, contohnya apabila dibuang pada saluran, maka minyak dapat mengendap dan menyumbat saluran air.

Salah satu upaya untuk mengelola minyak jelantah adalah dengan mengkonversinya menjadi Biodiesel. Proses ini telah dilakukan dengan sukses di China, Jepang, US, dan berbagai negara di Eropa (Zhang dkk., 2014, 2015). Di Indonesia, proses ini telah dilakukan di Bogor, Padang, dan Bali (Kharina dkk., 2018; Kurnia \& Hadiguna, 2016). Di Jakarta, rantai pasok pengelolaan minyak jelantah dijelaskan dalam Peraturan Gubernur nomor 167 tahun 2016 namun implementasinya belum memuaskan. Faktor utama kurang baiknya rantai pasok tersebut adalah kurangnya kuantitas minyak jelantah yang terkumpul (Jachryandestama dkk., 2021; Kurnia \& Hadiguna, 2016).

Salah satu rekomendasi untuk Peraturan Gubernur tersebut adalah untuk melibatkan sektor rumah tangga dalam rantai pasok. Hasil penelitian DLH Provinsi DKI 2019 bahwa rumah tangga menggunakan 323.748,50 L/hari sehingga berpotensi menghasilkan limbah minyak jelantah sejumlah 210.465, 31 L/hari. Perhitungan ini mengasumsikan 65,01\% minyak goreng berpotensi menjadi minyak jelantah. 
Apartemen Bassura City adalah tempat tinggal bangunan bertingkat di daerah Jakarta Timur yang terdiri atas sembilan tower. Masingmasing tower terdiri atas 500 - 1.000 unit dengan tingkat okupansi yang tinggi dan tingkat penghasilan sedang. Apartemen Bassura City berpotensi memiliki timbulan minyak jelantah yang tinggi namun belum memiliki sistem pengelolaan minyak jelantah. Hal ini mengkhawatirkan karena dalam apartemen, jika minyak jelantah dibuang langsung ke saluran pembuangan maka minyak dapat membeku dan menjadi lapisan-lapisan tebal yang mengendap di dinding sistem saluran pembuangan (Filip \& Brezoczki, 2019).

Apartemen Bassura City umumnya berisikan rumah tangga dengan pendapatan sedang yang berdasarkan laporan Dinas Lingkungan Hidup pada tahun 2020 berpotensi menimbulkan 0,04 liter minyak jelantah/orang/hari. Jika diasumsikan terdapat 50\% okupansi atau 300 unit/tower, yang dihuni 1 orang, maka diestimasikan setiap tower akan menimbulkan 12 liter/hari atau 84 liter/minggu.

Dengan demikian, sebagai bagian dari Tri Dharma Perguruan Tinggi, Masjid Al-Falah yang terletak di area Apartemen Bassura City dipilih menjadi mitra kegiatan pengabdian kepada masyarakat. Mitra kedua adalah pengumpul minyak jelantah yaitu BeliJelantah yang aktif melakukan kegiatan pengumpulan di area Jakarta Timur dan Jakarta Selatan.
Tujuan dari kegiatan pengabdian kepada masyarakat ini adalah untuk meningkatkan kesadaran dan perilaku masyarakat akan bahaya minyak jelantah, meningkatkan kesadaran akan potensi daur ulang minyak jelantah, dan membangun sistem pengumpulan dan penyaluran minyak jelantah di area Apartemen Bassura City.

\section{METODOLOGI}

Untuk membangun sistem pengumpulan minyak jelantah yang berkelanjutan, pelaksanaan kegiatan pengabdian kepada masyarakat ini dilakukan dalam lima tahap: tahap partnership, tahap perencanaan prosedur, tahap sosialisasi, tahap monitoring dan evaluasi (Gkouskos \& Tsoutsos, 2018). Metodologi ini memastikan keberlanjutan sistem dalam segi sosial, ekonomi, dan lingkungan.

\section{A. Tahap Partnership}

Tahap partnership mempertemukan stakeholder sehingga hingga tercapainya keputusan yang strategis tentang proses pengembangan sistem. Stakeholder sistem adalah Jamaah Masjid Al-Falah, Masjid Al-Falah, BeliJelantah, Dinas Lingkungan Hidup (DLH) Jakarta Timur, dan Universitas Bakrie. Adapun keseluruhan warga Apartemen Bassura City, pihak manajemen serta Perhimpunan Pemilik dan Penghuni Rumah Susun (P3SRS) Apartemen Bassura City dapat menyusul dalam mendukung dan memperbesar sistem pengumpulan minyak jelantah. 
Aspek ekonomi yang dipertimbangkan yaitu harga minyak jelantah antara Masjid Al-Falah dengan BeliJelantah dan nilai insentif yang akan diberikan kepada warga. Sebagai pengumpul sedang, BeliJelantah menghargai minyak jelantah Rp4.000,00/liter dan menyediakan peralatan pengumpulan untuk komunitas. Penelitian DLH Pem Prov DKI 2019 menunjukkan bahwa 75\% rumah tangga berkenan untuk menyedekahkan minyak jelantahnya sehingga insentif bagi warga akan diatur berdasarkan permintaan.

\section{B. Tahap Perencanaan}

Pada tahap perencanaan dilakukan untuk menentukan sistem pengumpulan minyak jelantah yang tepat di masjid. Perencanaan diawali dengan studi literatur, survey mitra, dan wawancara awal dengan Dewan Kemakmuran Masjid (DKM) Masjid Al Falah Bassura City dan BeliJelantah. Hal ini dilakukan untuk mengetahui secara langsung kondisi dan fasilitas yang tersedia untuk analisis kebutuhan.

Sistem pengumpulan yang diimplementasikan merupakan bagian dari rantai pasok yang dideskripsikan dalam Peraturan Gubernur No.167 Tahun 2016. Rantai pasok ini sesuai dengan rantai pasok terbalik yang umum digunakan dalam pengumpulan limbah (Jayakumar, 2017). Gambar 1 menunjukkan peran Masjid Al-Falah sebagai pengumpul komunitas/skala kecil dan BeliJelantah sebagai pengumpul skala sedang.

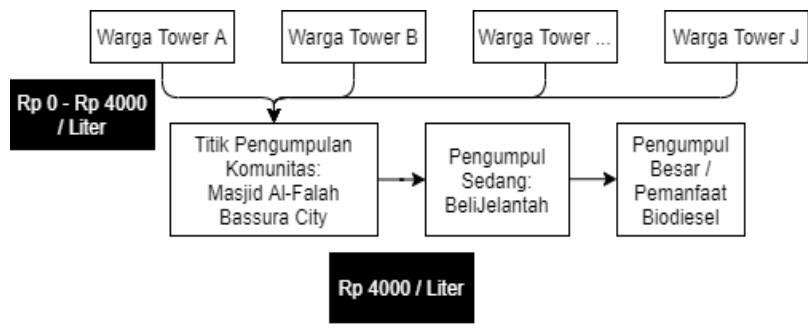

Gambar 1. Alur Pengelolaan dan Harga Minyak Jelantah di Area Bassura

Terdapat dua sistem pengumpulan minyak jelantah yaitu sistem pengumpulan pintu-kepintu (jemput) dan sistem tempat pengumpulan umum (antar) dan masing-masing memiliki kelebihan dan kekurangan (Gkouskos \& Tsoutsos, 2018). Sistem pengumpulan pintu-ke-pintu tidak dapat diterapkan dalam area apartemen karena pergerakan di area apartemen sangat terbatas karena alasan keamanan dan Covid-19. Dengan demikian, sistem tempat pengumpulan umum adalah sistem pilihan.

Kelebihan sistem tempat pengumpulan umum adalah biaya logistik yang lebih rendah dan warga semakin biasa dan termotivasi untuk mendaur ulang. Kelebihan ini sangat bermanfaat bagi masjid yang menginginkan jamaahnya untuk rutin beraktivitas di dalam kegiatan masjid.

Kekurangan dari sistem ini adalah tidak ada kontrol langsung atas kualitas bahan baku, risiko tinggi kejadian pencurian/vandalisme UCO, serta kebersihan tempat sampah terbatas, yang terkait dengan tumpahan atau pengiriman UCO yang salah. Menanggulangi hal ini, mitra BeliJelantah bersedia menerima minyak jelantah tanpa mempertimbangkan kualitas. Mitra Masjid AlFalah bersedia untuk menyediakan tempat yang dijaga keamanan dan kebersihannya oleh 
Marbot Masjid. Dengan demikian , titik pengumpulan minyak jelantah dinyatakan baik.

Dalam wawancara awal diidentifikasi bahwa warga memerlukan kontainer untuk mengumpulkan minyak jelantah di rumahnya. Hasil penelitian DLH Pem Prov DKI 2019 bahwa rumah tangga dengan pendapatan sedang menimbulkan 0,04 liter/orang/hari sehingga sebuah keluarga akan menghasilkan lebih dari 2 liter/bulan. Dengan demikian, masjid Al-Falah menyediakan jerrycan berukuran 2 liter untuk warga.

Estimasi timbulan minyak jelantah per minggu dikalkulasi untuk menentukan jumlah jerrycan besar yang diperlukan dan potensi insentif bagi masjid. Dengan estimasi 84 liter/minggu, BeliJelantah memastikan setidaknya terdapat lima jerrycan ukuran 18 liter di masjid pada setiap saat. Dengan demikian, masjid berpotensi mendapatkan Rp336.000,00.

\section{Tahap Sosialisasi}

Sosialisasi sistem pengumpulan minyak jelantah terbagi menjadi sosialisasi pasif dan sosialisasi aktif seperti disajikan pada Gambar 2 dan 3.

\section{Sosialisasi pasif dilakukan dengan} menggunakan standing banner yang diletakkan dekat pintu masuk masjid, flyer yang diletakkan dekat kotak amal dan dibagian kepada para tenant dan warga sekitar, juga poster di beberapa titik. Dengan demikian, jamaah dapat segera membaca konten edukasi minyak jelantah.

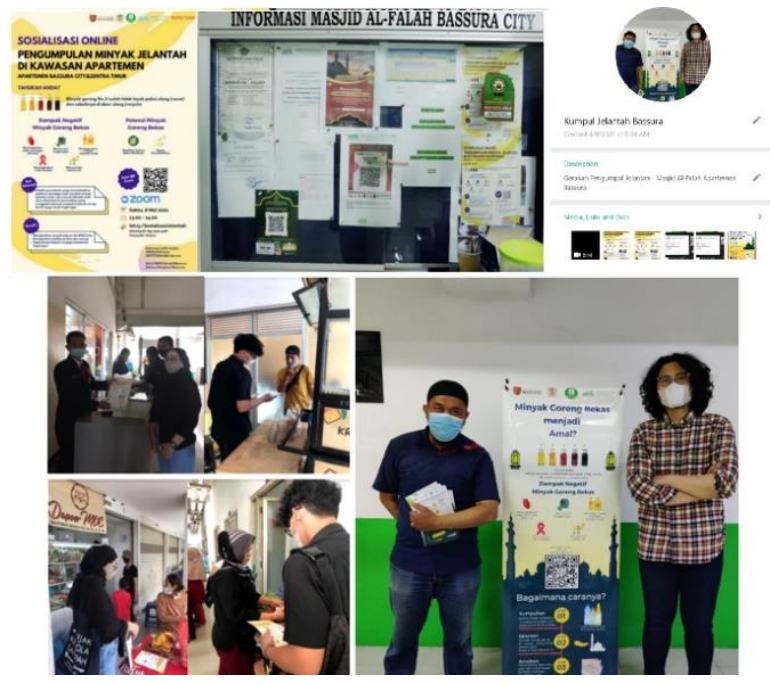

Gambar 2. Sosialiasi Kegiatan dengan Banner dan Flyer

Sosialisasi aktif dilakukan tim adimas Universitas Bakrie dengan menyelenggarakan kegaiatan online, untuk meningkatkan pemahaman warga dan stakeholder tentang bahaya minyak jelantah. Sebuah whatsapp group dengan tujuan mengingatkan warga untuk terus mengelola minyak jelantah dengan bijak.

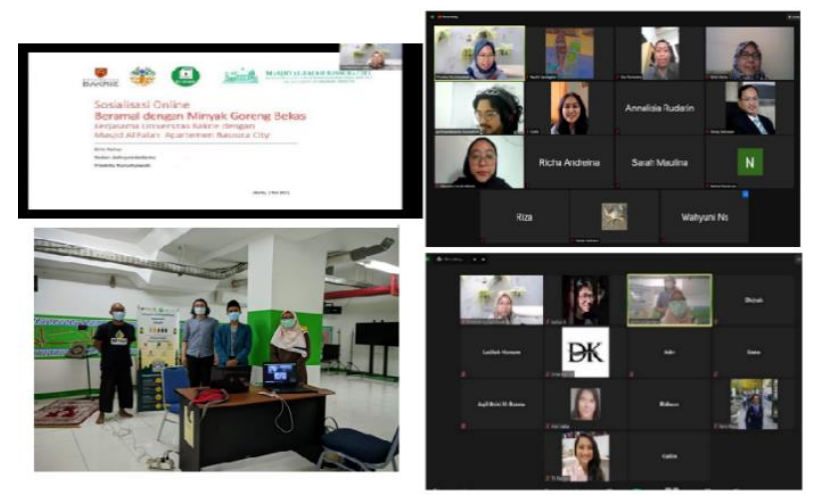

Gambar 3. Sosialiasi Kegiatan dengan Zoom Meeting

Sosialisasi aktif dilakukan Masjid Al-Falah dengan mengintegrasikannya dalam pengumuman masjid. Marbot masjid juga aktif mensosialisasikan kegiatan kepada warga dan tenant. 


\section{Tahap Monitoring dan Pendampingan}

Pengumpulan minyak jelantah dapat dilakukan kapanpun selama Masjid Al-Falah beraktivitas. Pendampingan pelaksanaan program pengumpulan dan penyaluran minyak jelantah dilakukan selama 1 bulan. Monitoring dan evaluasi praktek pengelolaan minyak jelantah juga dilakukan oleh tim pengabdian masyarakat untuk memastikan praktek tata kelola berjalan dengan baik.

Satu bulan setelah sistem pengumpulan diimplementasikan, dua minggu setelah rangkaian sosialisasi, sebanyak 33 liter minyak jelantah terkumpul di Masjid Al Falah. Minyak jelantah ini diuangkan menjadi Rp132.000,00 yang seluruhnya diberikan kepada DKM Al-Falah karena seluruh warga tidak meminta insentif. DKM Al-Falah menyimpan uang tersebut untuk pengumpulan minyak jelantah periode berikutnya untuk menjamin keberlanjutan sistem. Beberapa kegiatan monitoring dapat dilihat pada Gambar 4.

\section{E. Tahap Evaluasi}

Tahap evaluasi bertujuan untuk meningkatkan efisiensi dan efektivitas sistem pengumpulan. Gambar 5 adalah cross functional flowchart dari sistem pengumpulan minyak jelantah. Flowchart digunakan agar pengembangan sistem dapat mudah dilakukan (Granfelt, 2017).
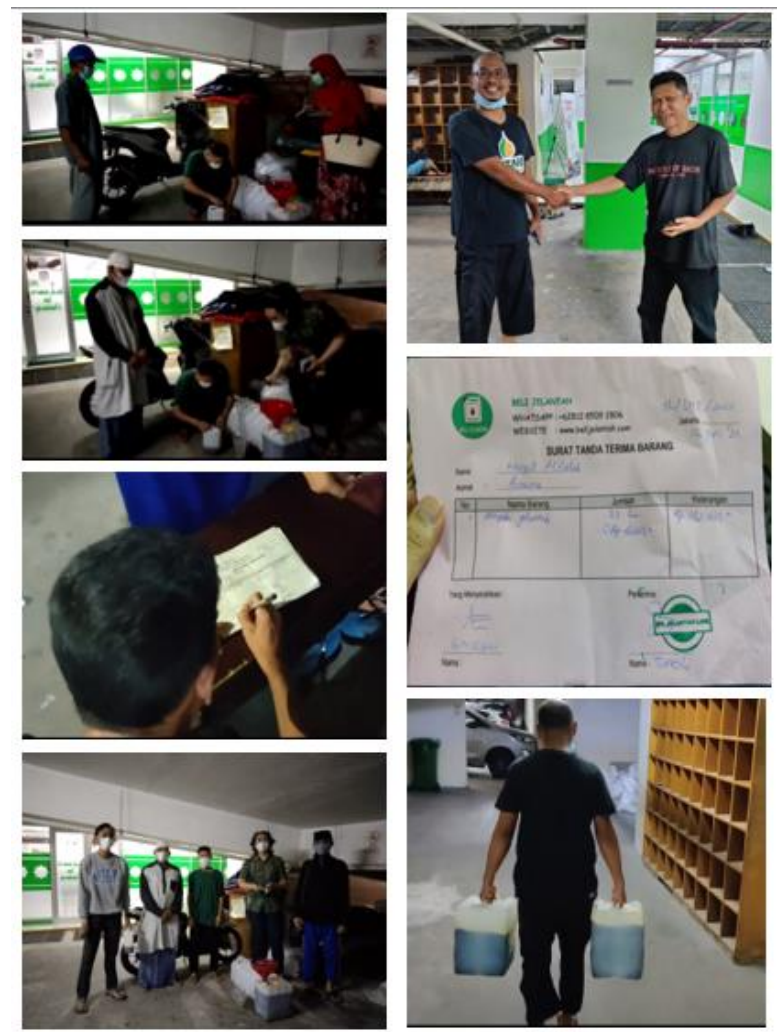

Gambar 4. Program Pendampingan dan Monitoring Kegiatan

Sistem pengumpulan berhasil memenuhi delapan kriteria pengumpulan minyak jelantah yang baik yaitu (Gkouskos \& Tsoutsos, 2018):

1. Mudah diakses oleh warga

2. Lingungan dengan keluarga dan anak-anak

3. Dekat dengan tempat sampah lainnya

4. Memiliki penerangan yang memadai

5. Mudah dijaga kebersihannya

6. Tidak mengganggu perjalanan

7. Jarak yang cukup jauh dari tanah untuk mencegah kebocoran untuk terserap tanah

8. Dapat diakses dengan mudah oleh pengumpul 


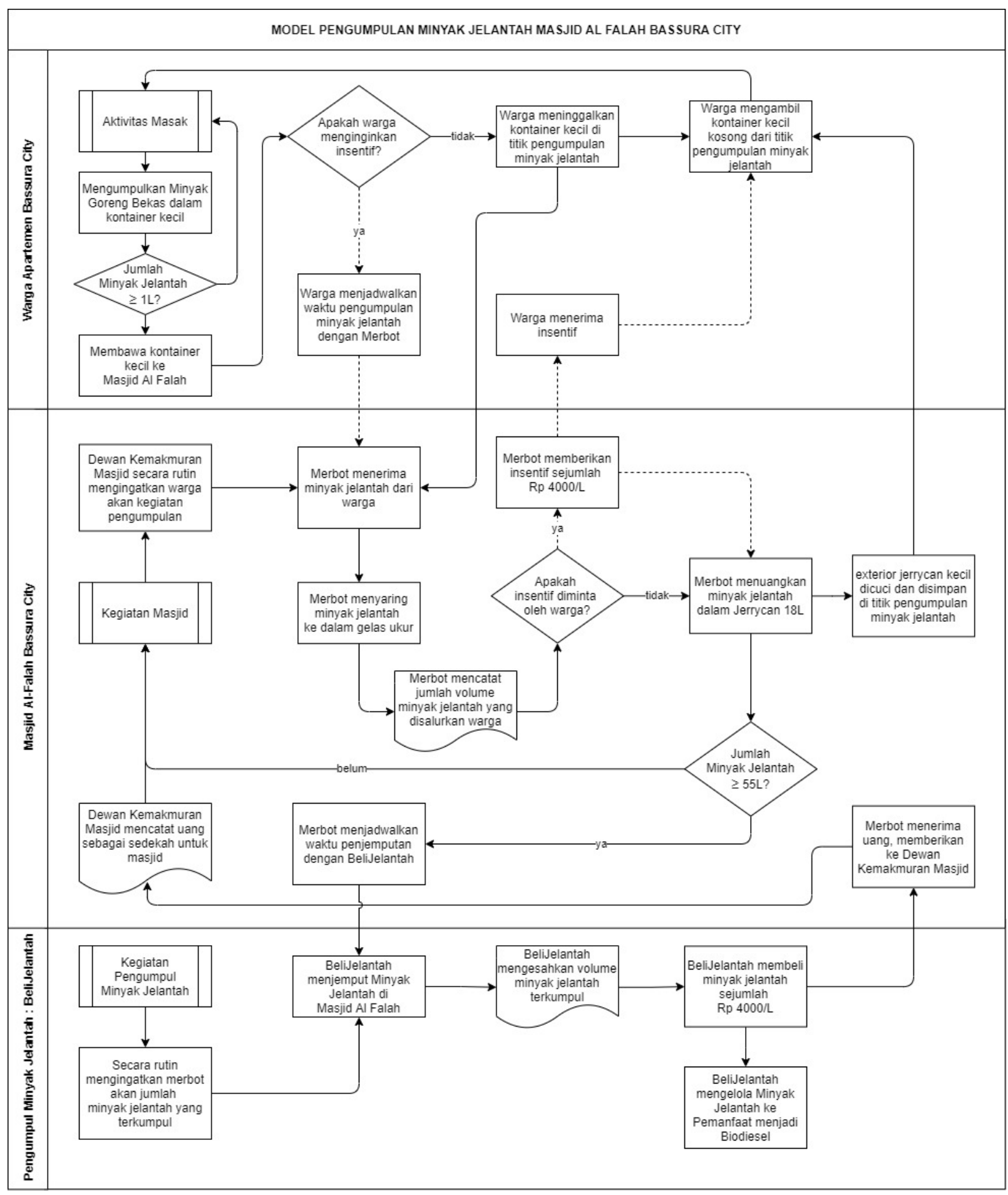

Gambar 5. Cross Functional Flowchart Pengumpulan Minyak Jelantah

\section{HASIL DAN PEMBAHASAN}

Tujuan dari kegiatan pengabdian kepada masyarakat ini adalah untuk meningkatkan kesadaran dan perilaku masyarakat akan bahaya minyak jelantah, meningkatkan kesadaran akan potensi daur ulang minyak jelantah, dan membangun sistem pengumpulan dan penyaluran minyak jelantah di area Apartemen Bassura City. 
Pada 2 kali tahap sosialisasi diketahui bahwa pada umumnya warga apartemen Bassura City telah memahami bahaya minyak jelantah terhadap Kesehatan. Namun, mereka belum memahami bahaya minyak jelantah terhadap lingkungan. Warga juga sebelumnya tidak mengetahui bahwa limbah minyak jelantah masih memiliki nilai dan dapat diolah menjadi biodiesel.

Sebelumnya, warga apartemen Bassura City tidak mengelola limbah minyak jelantahnya dengan baik. Minyak jelantah langsung dibuang ke saluran pembuangan atau dibuang ke tempat sampah. Dengan adanya sistem pengumpulan minyak jelantah, warga menjadi sadar bahwa limbah minyak jelantah masih memiliki nilai ekonomi. Hal ini terlihat dalam masa pendampingan yang relatif singkat, sudah ada warga yang ikut berpartisipasi dalam pengumpulan minyak jelantah sampai sekitar 33 liter bahkan menyedahkan seluruh kompensasi kepada pihak masjid. Volume minyak jelantah yang terkumpul pada awal program ini cukup signifikan bagi komunitas yang aktifitas menggorengnya tidak terlalu tingggi dibanding warga di pemukiman umum, namun tetap sadar akan tata kelola minyak jelantah yang tepat. Penyediaan jerrycan kosong berstiker informasi terkait minyak jelantah yang disediakan tim diminati oleh warga mau pun tenant untuk turut serta dalam program ini. Komitmen dari tim abdimas sebagai pendamping di WAG Kumpul Jelantah terus membahas dan menjawab pertanyaan warga seputar program ini. Di lain pihak, DKM Masjid Al Falah dan marbot terus mensosialiasikan tata Kelola minyak jelantah di area apartemen dengan tetap memasang poster mading masjid, bannner, pengumuman kepada jamaah secara berkala dan melakukan pelayanan setiap warga yang hendak mengumpulkan minyak jelantah. Pihak warga yang sudah mengumpulkan juga bersedia mengajak tetangga unit apartemen lain dan menyebarkan informasi akan perlunya tata kelola minyak jelantah yang tepat.

Masjid adalah tempat pengumpulan minyak jelantah yang baik karena memiliki tingkat keamanan yang tinggi karena umumnya dijaga oleh marbot. Terlebih, sedekah adalah konsep yang tidak asing bagi jamaan masjid sehingga penjualan minyak jelantah dapat sepenuhnya dimanfaatkan oleh masjid. Dan menurut pelaporan dari pihak masjid, pengumpulan tetap berjalan baik setelah masa pendampingan dan ini menandakan kesadaran warga meningkat.

Pengumpulan minyak jelantah berikutnya akan dapat dilanjutkan oleh warga dan pihak DKM Masjid dengan langsung berkoordinasi dengan BeliJelantah dengan pengambilan minimum 2-3 jeriken bervolume $18 \mathrm{~L}$ atau setara 36 - 54 L agar dapat dijemput hari kerja dan weekend.

\section{KESIMPULAN}

Sistem pengumpulan minyak jelantah merupakan bagian yang penting dari rantai pasok 
minyak jelantah menjadi biodiesel. Warga Apartemen Bassura City melalui Masjid Al-Falah Bassura City sudah melakukan inisiasi keterlibatan aktif dalam rantai pasok sebagai penghasil minyak jelantah.

Warga sudah mendapat pemahaman akan bahaya dan potensi minyak jelantah dari sosialisasi aktif dan pasif yang dillakukan. Hal ini terbukti dengan terkumpulnya minyak jelantah sebanyak 33 liter yang diuangkan oleh BeliJelantah menjadi Rp134.000,00 dan seluruhnya disedekahkan ke pihak Masjid Al Falah Bassura City.

Keberlanjutan pengumpulan minyak jelantah akan dilakukan oleh warga dan pihak DKM Masjid dengan langsung berkoordinasi dengan BeliJelantah dengan pengambilan minimum 2 - 3 jeriken bervolume $18 \mathrm{~L}$ agar dapat dijemput hari kerja dan weekend.

\section{UCAPAN TERIMA KASIH}

Pengabdian masyarakat ini dapat terselenggara dengan baik berkat dukungan Hibah Internal Lembaga Pengabdian Masyarakat Universitas Bakrie dan stakeholder terkait, yaitu Manajemen Apartemen Bassura City, Masjid Al Falah Bassura City, Dinas Lingkungan Hidup Jakarta Timur, dan BeliJelantah.

\section{DAFTAR PUSTAKA}

Filip, G. M., \& Brezoczki, V. M. (2019). About Used Cooking Oil - Social Aspects From Baia Mare Town. Scientific Bulletin Series D:
Mining, Mineral Processing, Non-Ferrous Metallurgy, Geology and Environmental Engineering, 33(1), 31-37.

Gkouskos, Z. K., Tournaki, S. K., Giamalaki, M. P., \& Tsoutsos, T. D. (2018). From Used Cooking Oil to Biodiesel. Full Supply Chain Demonstration. Conference on Renewable Energy Sources \& Energy Efficiency, 376-385. Granfelt, S. A. (2017). Process Flow Documentation A Flowchart Guide For Micro \& Small Business. Elsevier.

Peraturan Gubernur Provinsi Daerah Khusus Ibukota Jakarta Nomor 167 Tahun 2016 Pengelolaan Limbah Minyak Goreng. 26 Agustus 2016. Jakarta.

Jachryandestama, R., Nursetyowati, P., Fairus, S., \& Pamungkas, B. (2021). Risk Analysis in Jakarta's Waste Cooking Oil to Biodiesel Green Supply Chain Using Group Ahp Approach. Sinergi, 25(2), 227-236.

Jayakumar, A. A. (2017). A Review of Mathematical Models for Supply Chain Network Design. International Journal of Innovative Research in Advanced Engineering, 12(4), 2349-2163.

Kharina, A., Searle, S., Rachmadini, D., Kurniawan, A. A., \& ... (2018). The Potential Economic, Health and Greenhouse Gas Benefits of Incorporating Used Cooking Oil into Indonesia's Biodiesel. Washington: The International Council on Clean Transportation. 
Kurnia, R., \& Hadiguna, R. A. (2016). Penentuan Prioritas Risiko pada Rancangan Rantai Pasok Biodiesel dari Minyak Goreng Bekas di Kota Padang. Jurnal Rekayasa Sistem Industri, 5(1), 15-25.

Zhang, H., Aytun Ozturk, U., Wang, Q., \& Zhao, Z. (2014). Biodiesel Produced by Waste Cooking Oil: Review of Recycling Modes in China, The US and Japan. Renewable and Sustainable Energy Reviews, 38, 677-685.
Zhang, H., Ozturk, U. A., Zhou, D., Qiu, Y., \& Wu, Q. (2015). How to Increase The Recovery Rate for Waste Cooking Oil-to-Biofuel Conversion: A Comparison of Recycling Modes in China and Japan. Ecological Indicators, 51, 146-150. 